WellBeing International

WBI Studies Repository

1984

\title{
The Origins of Empathy and Altruism
}

\author{
Carolyn Zahn-Waxler \\ National Institute of Mental Health \\ Barbara Hollenbeck \\ National Institute of Mental Health \\ Marian Radke-Yarrow \\ National Institute of Mental Health
}

Follow this and additional works at: https://www.wellbeingintlstudiesrepository.org/acwp_habr

Part of the Animal Studies Commons, Behavior and Ethology Commons, and the Comparative Psychology Commons

\section{Recommended Citation}

Zahn-Waxler, C., Hollenbeck, B., \& Radke-Yarrow, M. (1984). The origins of empathy and altruism. In M.W. Fox \& L.D. Mickley (Eds.), Advances in animal welfare science 1984/85 (pp. 21-41). Washington, DC: The Humane Society of the United States.

This material is brought to you for free and open access by WellBeing International. It has been accepted for inclusion by an authorized administrator of the WBI Studies Repository. For more information, please contact wbisr-info@wellbeingintl.org.

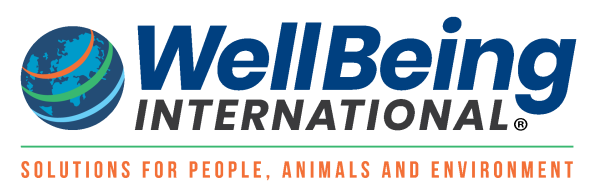




\section{THE ORIGINS OF EMPATHY AND ALTRUISM}

\section{Carolyn Zahn-Waxler, Barbara Hollenbeck and Marian Radke-Yarrow}

National Institute of Mental Health

Bethesda, MD 20205

Empathy and altruism are most commonly thought of as forms of compassion that human beings express toward one another. However, emotions and behaviors reflecting apparent concern for others occur within other species and across species as well. Although not without controversy, ethologists and sociobiologists (e.g., Wilson 1975) have identified many behaviors in other animals and insects that may be viewed as prosocial or altruistic (e.g., cooperative efforts of bees, warning calls of many species, rescue behaviors of whales, certain acts of mammalian caregivers toward their young, etc.). There are fewer signs of altruism across species. Some animals can be trained to protect, defend and help others (usually humans) in distress. Animal owners sometimes indicate that their pets show emotional concern for others. In observing parent-child interaction in the home we have seen emotionally distressed pets hovering over persons feigning distress in situations where we are measuring the child's capacity for empathy. The recent spate of research on animal facilitated therapy attests to the capacity of animals to provide comfort to persons suffering from a variety of physical and emotional problems.

Altruism across species is probably most commonly seen, however, in human behavior toward other animals. Humans are known to help, comfort, share with, protect and defend animals. There have even been reports of loss of human life, for example, in the process of rescu- 
ing animals. There is also enormous variation among humans in their sensitivity to their own animals, their commitment to principles of humane treatment, (Miller 1983) and their concern for preservation of wildlife. It is difficult to account for these individual differences in human beings' capacities for compassionate versus aggressive, exploitative attitudes and behaviors toward others, for the origins are multiple and complex.

In a review of the altruism literature, Burleson (in press) concluded that comforting activity by humans is most likely to occur or occurs more sensitively when the distressed, needy other (a) has a close, caring relationship with the comforter, (b) shows salient signs of distress, and (c) is perceived by the comforter as similar to himself or herself. In order to facilitate altruism then, it would be important, to identify both the attributes we have in common with others (animal as well as human) and the factors that promote caring relationships. The earlier in development the emotional ties are established, presumably the more deeply engrained will be the compassion. The purpose of this chapter is to explore these processes in greater detail.

We will describe theories and research that try to explain the development, especially in children, of sensitivity to the needs of others. Are children born with empathy? Is it instinctive or learned? What kinds of changes do humane feelings and behaviors undergo as children develop? How do the environments in which children are reared determine whether they will be more or less likely to show concern and to assume responsibility for the welfare of others? We have examined these issues in a series of studies of (a) the early origins of emotional concern (empathy) and (b) the translation of concerned feelings into altruistic behaviors such as helping, sharing, and comforting. Because of an interest in the development of generalized altruism, we have studied children's prosocial orientations toward humans and animals, in many settings and over long intervals of time. We will consider the implications of theories and research findings for humane attitudes and treatment.

Empathy refers to the capacity to feel what another is feeling. Examples include the sadness felt when tragedy strikes a friend or the pleasure vicariously experienced in relation to another's joy. It is, then, the sharing of an emotional experience. While it is not restricted to the contagion of any particular emotion, the term most commonly does refer to the emotional concern aroused by the suffering of another living being. This is where our research interest has centered-on the development of emotions and behaviors reflecting concern for the welfare of others. Empathy has many functions. It is viewed by some as essential to all social interactions and relationships because it informs us about the inner world of the other person (Meade 1934). It has been 
suggested that empathy is critical to the process of insight, for one sees oneself through the eyes of the other via empathy (Dymond 1945). In some theories of moral development (e.g., Hogan 1973) empathy is a necessary component of mature, moral functioning. Empathy may be a fundamental motivator in eliciting altruistic and prosocial behaviors and inhibiting aggressive ones (Hoffman 1976; Feshbach and Feshbach, in press). And empathy is viewed as a critical condition of effective therapeutic intervention in psychotherapy (Rogers 1957) and psychoanalysis (Olinick 1980).

Empathy is hypothesized to have both a cognitive and affective component, i.e., (a) the emotional experiencing or sensing of the other's experience and (b) the intellectual understanding or interpretation of what that experience means (Hoffman 1976). In very young children and in animals as well, where symbolic capacities are limited, we would expect the emotional component of empathy to predominate. In theory, both the cognitive and emotional aspects of empathy should enhance the likelihood of caring for another in need and hence of assuring humane treatment. And with increases in intellectual abilities and competencies throughout childhood, compassionate behavior, too, should increase. However, this is not always the case. Another person's distress may be so frightening or painful when experienced empathically, that it may turn the viewer away from the victim's plight. Intense emotional involvement and preoccupation with another's problems may enmesh one in that distress so completely that it interferes with appropriate emotional concern and provision of constructive help. Further, we may mistakenly project our own emotions onto another with whom we think we are empathizing. Finally, knowledge of another's needs, emotions, and desires may be used to manipulate or control another person, to prey on their vulnerabilities, or to intellectualize, and hence deny, the experience.

Prosocial behaviors, acts that benefit another in need (e.g., help, sharing, cooperation, comfort, protection, rescue, and defense) also represent complex and diverse processes. They may or may not be the behavioral counterparts to feelings of concern. Helping can be an intrusive and unwanted act of domination, defense of a victim often contains elements of aggression and anger, sharing may be done with expectations of reciprocity, comforting may be motivated by guilt or righteous indignation, cooperation may be in the services of intent ultimately to exploit a partner. These complexities suggest (a) that there may be optimal levels of expression of concerned feelings and behaviors, and (b) that some types of prosocial behavior are more likely than others to reflect altruism or generalized humane behavior. It is important to try to distinguish those emotions and behaviors that 
reflect genuine concern, because this attribute is particularly important in assuring humane treatment.

\section{THEORIES OF THE DEVELOPMENT OF EMPATHY AND ALTRUISM}

There are four major theories that have been used to explain the development of altruism. They variously emphasize the importance of (1) guilt and conscience, (2) cognitive development, (3) instinct, and (4) learning and environmental processes, to explain the origins and maintenance of prosocial behavior.

\section{PSYCHOANALYTIC THEORY}

In psychoanalytic theory, the concept of identification has been used to explain how the values and mores of society become internalized, and hence why children become prosocial. The child is believed to become altruistic, to share and cooperate, either because of guilt resulting from moral transgressions or through the internalization of ego ideals (i.e., positively valued behaviors in others). The concept of pathological altruism also derives from psychoanalytic theory. The emphasis is on unconscious, inner forces that drive the behaviors. This approach has produced relatively few studies, but it seems reasonable to assume that prosocial behaviors (e.g., help sharing and comfort) for some persons and on some occasions result from feelings of guilt or an overactive conscience.

\section{COGNITIVE THEORY}

In cognitive-developmental theory which originated with Piaget (1932) the emphasis has been on children's social-inferential abilities as a prerequisite for prosocial behavior. The young child is viewed as egocentric, assuming that others think and feel the same way $s / h e$ does. A certain level of intellectual growth or maturation thus is necessary before the child becomes capable of understanding another's point of view and hence of being altruistic. This approach produced many studies in which children's abilities to take others' social roles or perspectives and their abilities to reason about moral issues were examined in relation to prosocial actions. The assumptions were that the ability (a) to interpret accurately another's needs or (b) to attain a high level (stage) of moral reasoning was necessary for a child to show con- 
cern reflected in actual behavior. The results of these research projects are mixed (see reviews by Radke-Yarrow, Zahn-Waxler and Chapman 1983; Shantz 1983) with no strong evidence for the hypothesized connection between social-cognitive capacities and altruistic acts. In other words, one can understand the nature of another's distress without doing anything about it and one can behave in a caring way without highly developed cognitive capacities.

In both psychoanalytic and cognitive theories, there is a long period of early development in which self-concern is presumed to predominate: Consideration for others would not be expected from children until they were at least five to seven years old. Two other theories, ethological/evolutionary and learning theories, do not highlight a particular age or stage of development necessary for altruism to occur. They are considered in greater detail throughout this chapter because of their special relevance to humane education: The ethological approach because it provides an evolutionary perspective and identifies those attributes that we have in common with others (human and animal) and the learning approach because it begins to identify specific mechanisms by which empathy and altruism can be taught and learned.

\section{LEARNING THEORY}

In learning theory, the emphasis has been more on the overt, observable prosocial behavior of the child rather than on reasoning and inner motives. In initial formulations, prosocial behavior was presumed to be acquired in the same way as other learned behaviors - through processes of conditioning reinforcement, and modeling (see Radke-Yarrow, Zahn-Waxler, and Chapman 1983). Over time, conceptions of learning were expanded to include the influence of other socialization processes (e.g., nature of parental discipline; specific instruction; institutionalized, cultural norms and so on). For example, different cultures and subcultures have quite different norms that are communicated to the child about cooperative, individualistic and competitive behaviors and what is appropriate balance between them (Madsen and Shapira 1977). Learned norms of responsibility (i.e., that it is our duty to help) and norms of reciprocity (i.e., "I'll help you if you help me") are thought to be culturally determined and learned in institutional settings (school, church, home, etc.).

The values of society impinge most directly on young children through their parent's attitudes and philosophies about moral and altruistic behaviors as well as through their specific teaching and caregiving practices. Some of these practices include (a) what care- 
givers model or convey in their own behavior about empathy and altruism, (b) what they preach about consideration for others, (c) their general nurturance or warmth toward the child and their own empathy when the child is distressed, (d) their teaching and control practices, when their children cause distress to another (e.g., physical punishment, love withdrawal, explanation and reasoning) (e) the use of praise and punishment, (f) the use of attributions (such as "you are mother's good helper"), and (g) the creation of environments that promote prosocial behavior or make caring possible. Generalizations or formulas for how to produce a prosocial child are difficult and sometimes hazardous, but the bulk of evidence implicates the following caregiver variables as important-the modeling of altruism to others, nurturance toward the child, use of reasoning (and firm discipline when the child hurts others), direct instruction in how to help, and reinforcement for helping (Eisenberg 1983; Radke-Yarrow, Zahn-Waxler and Chapman 1983). In later sections we will consider in greater detail how some of these variables influence the development of empathy and altruism in children. Another approach to the socialization question has been taken by investigators who have examined parental and societal factors that promote or inhibit aggression rather than prosocial behavior. A brief overview of these findings indicates that parental permissiveness and inconsistency are associated with high levels of aggression in their children; also predictive of cruelty in childhood are high levels of parental aggression and abusiveness, both toward the children and others as well (see Parke and Slaby 1983, for a detailed review of this literature). The learning/socialization perspective holds special promise for humane education because it can identify processes that may be alterable and hence may enhance the child's prosocial tendencies.

\section{BIOLOGICAL THEORIES}

Ethological/evolutionary approaches, on the other hand, hold promise for understanding the biological bases of altruism and possibly for understanding empathic relationships between humans and animals. In this view, altruism is built into species and some forms of altruism are adaptive for survival. Ethologists emphasize the fact that humans like other animals, are born with behavioral and emotional tendencies that enhance their own likelihood of survival and hence the continuation of the species. Even though human infants are more helpless than the young of any other mammalian species, they are well equipped with reflexes and behaviors of significance for survival (e.g., rooting, sucking, clinging, following). The distress cries of infants are 
present at the moment of birth: They provide for very effective means of eliciting attention, sympathy, help, and comfort from adults. In all mammals this distress cry or isolation call is a stimulus for caregiving and comfort. It served originally to maintain social cohesion by maintaining maternal-offspring contact. The distress cry of mammals is also a constant reminder that animals other than ourselves do have feelings and are capable of suffering.

There are many characteristics that humans have in common with other mammals that may contribute to maintenance of social contact and hence, possibly, to the development of empathy as well (e.g., social play, nursing, separation distress). Distress is a universal emotion expressed across all mammalian species. Distress is also a stimulus for acts of altruism. It has the potential for evoking an emotional, possibly empathic, response in some other members of the same species. If there is sufficient similarity in expressions of distress across different mammalian species, this may be a powerful biological mechanism reminding us that some of the distresses and needs of other species are similar to our own. This recognition of communality might help to promote empathy across species. There is little or no research designed to explore humans' reactions to the cries of other animals. In one of our studies (Zahn-Waxler, Friedman, and Cummings 1983) preschool and elementary school-age children overheard cries of premature and normal babies. It was not uncommon for children initially to mistake the cries, particularly those of the less developed, premature infants, for cries of animals and birds (sheep, donkeys, cats, goats, even kangaroos and turkeys). This did not deter the children from expressing empathy toward the infants with unusual (animal-like) cries. Distress cries, however, should be seen as a necessary but not sufficient condition for eliciting empathy. There are also studies to indicate that distress cries elicit aggressive behavior in some caregivers. Physical abuse and neglect of distressed offspring have been reported in primates as well as humans.

MacLean (1982) has hypothesized that the capacity of mammals for nurturant caregiving toward their (distressed) offspring, in contrast to some reptilians who may abandon or eat their young, is the evolutionary forerunner to the development of empathy, conscience, and a sense of social responsibility. MacLean has attempted to identify those parts of the brain that are responsible for this caregiving. The limbic system is clearly basic for parental care and family affiliation in mammals. But the development of the prefrontal neocortex which is a much more recently evolved structure, has contributed to further development of the family, especially in primates. The added sector of neocortex gives human beings a capacity for foresight, which is believed to underlie our striving for the welfare of our own progeny 
and the progeny of others. Some scientists also have begun to speculate about neurochemical and hormonal bases of empathy and altruism and the brain circuitry that might be involved (Panksepp, in press).

\section{RESEARCH ON THE DEVELOPMENT OF GENERALIZED ALTRUISM}

Many of the processes that explain the origins and development of altruism are difficult to study directly. However, it is possible to study developmentally young children's responses to other's distress cries and hence examine their early capacities for empathy and caregiving. Such research has established the importance of both instinct and environment in the development of sensitivity to another's distress. Studies from the early 1900's demonstrated the possibility that even newborns may be predisposed to be receptive to distress; they are likely to cry, reflexively when they hear the cries of other babies. It was not clear, however, from these studies, whether children cried because they were empathic or because they were frightened or because the sounds of the crier were aversive and painful. More recent and experimentally sophisticated research designs (Simner 1971; Sagi and Hoffman 1976) have confirmed that there is special sensitivity to the cry, per se, and not just to the noisiness of the cry.

We have engaged in two kinds of studies of the development of altruism and empathy in over 175 young children. We have examined the origins and transitions (in one to two-and-a-half year olds) in prosocial patterns over time in natural settings (Zahn-Waxler and Radke-Yarrow 1982); and we have created different learning environments to determine which are most conducive to developing prosocial behavior based on concern for another's welfare (in three to five year olds) (Yarrow, Scott and Waxler 1973). In both studies we have been interested in how children respond to others in distress, because this represents the set of conditions most likely to evoke emotion (and hence possibly empathy and altruism). Both kinds of studies explore conditions that create generalized consideration for the welfare of others (i.e., caring for nonfamily as well as family members, for animals as well as humans).

\section{THE EARLY DEVELOPMENT AND SOCIALIZATION OF ALTRUISM}

A longitudinal study of one to two-and-a-half year olds examined children's responses to compelling distress situations. A sample of middle-class mothers was trained by research assistants to make 
systematic, narrative accounts and to tape record their observation reports. The mothers observed events of naturally occurring distress (e.g., pain, sadness, anger) that were either caused or witnessed by the children. This was done over a period of many months. Standard emotional incidents were also introduced. Each week either the mother or a home visitor acted out a distress emotion in the home. These procedures provided thousands of incidents which were then analyzed to determine (a) developmental changes in children's reactions to other's distress and (b) parental socialization practices that were more or less likely to produce altruism. Several hundred of these incidents involved reports of children's feelings and behaviors toward animals.

There are very distinct age changes in how children react to another's distress during the second year of life (Zahn-Waxler and Radke-Yarrow 1982). Children almost always are keenly aware of the distress and if they consistently do not notice, one wonders what is wrong. The youngest children are themselves likely to become distressed, in ways similar to the reflexive crying of newborns but not with such full-blow intensity. Just a little past the first year of life, children begin to comfort others in distress. This is a developmental landmark; an aversive experience in another person draws out a concerned, approach response from the child. Children's first prosocial acts are physical interventions: they pat and hug the victims, rub their hurts and so on. Children often begin to seek out guidance, reassurance, and information from their mothers when in these situations. There is also an explosion of prosocial activity at this time. Children's acts of compassion begin to take many different forms: acts of help, sharing, comforting, rescue, distraction, defense/protection, verbal sympathy, are now present in development. These reactions occur not only when children are innocent bystanders to the others' distress (e.g., watching mother stub her toe) but also when they have caused the harm (e.g., biting sister). The first prosocial interventions are largely, as one might expect, confined to family members. If families have pets, the animal sometimes become recipients of the child's first expressions of empathy. We have described the range of prosocial responses to humans elsewhere (Zahn-Waxler and Radke-Yarrow 1982). There is considerable overlap in the ways young children express kindness to animals and people. Table 1 provides illustrations from our data of the different kinds of prosocial behaviors that young children show to animals. And Table 2 provides examples of child's aggressive tendencies toward animals.

Virtually all of the children studied showed this early capacity for concern for the welfare of another being. This uniformity suggests that altruism is a biological given, "wired" in and ready for expression given sufficient physical, cognitive, and emotional growth. There were differences among children in the frequency and emotional intensity of 
Table 1

Compassionate Behaviors Toward Animals Shown by One-and-a-Half to Two-and-aHalf Year Old Children*

1. Child throws rubber toy at dog. Mother says, "Oh, you've hurt Bruno, poor Bruno." Child reaches over and hugs dog around the neck, then lies down on the hearth with the dog.

2. The dog begins to gasp for breath: Child runs over and smiled at first. Then he looks serious and throws himself on the dog to console him. Mother encourages him to get off. Mother comforts the dog by stroking its head and neck, and the child pats too.

3. Child pulls the dog's foot hard and the dog yelps. Mother says, "Oh, don't pull Suzy's foot like that." Child looks serious, touches foot and says "huirt." Mother becomes very excited because this is the first time child has used a word that expresses a feeling. She says, "Yes, it did hurt, but it doesn't anymore." Child then pats dog's paw very lovingly and gently, and hugs the dog.

4. Cat gets caught in the window well and girl cries with concern.

5. Dog sneezes and child brings Kleenex to blow its nose.

6. A dead goldfinch lies on the doorstep. Child points and said, "Birdie, birdie." and keeps looking at it with a furrowed brow-kind of sad-like.

7. The dog comes in making little crying sounds. The child turns around and says very sympathetically, "What's the matter, Lady? What's the matter?"

8. Mother is rough housing with the dog and hits a sore spot. He yelps, the mother tries to console and the girl comforts the dog as well.

9. Child steps on the dog's foot and he gave a snappy growl. Mother grabbed the dog, yelled at him and threw him in the basement. Father joined in. Child squawks back at parents in a loud harsh tone, i.e., she came to the defense of the dog by scolding her parents for yelling at the dog.

10. Child starts hitting the cat and pulls its tail. Mother moves child away and says, "No, we do not do that to cats, not at all. We treat them nicely. We never pull their tails and we never kick them." Then child begins to pat and kiss the cat.

11. Child is eating a snack and tries to share her animal crackers with the dog.

12. Child pulls dog's ears and dog gives a high little squeak. Mother notes that child doesn't seem to realize that those are squeaks of pain. So she has to tell him, "No, don't hurt the doggie; be gentle." Then he puts his arms around the dog's neck, puts his cheek to the dog's head and is sweet and gentle. (On another occasion like this, the mother explains but also slaps the child thus giving a mixed message.)

*Excerpted from mothers' observational records.

their altruism. This variability might result, in part, from differences in what children are being taught by their parents about responsiveness to the needs of others.

We examined three aspects of child-rearing and socialization that might be expected to influence young children's orientations to others in distress (Zahn-Waxler, Radke-Yarrow and King 1979). One concerns the nurturance or warmth of the caregiver and the sensitivity 
Table 2

Aggressive or Callous Behaviors Toward Animals Shown by One-and-a-Half to Two-and-a-Half Year-Old Children*

1. Mother calls the dog who won't come and mother says, "That dumb dog!" Child mimics mother's tone and says, "Get in here dumb dog."

2. Father is "real harsh" with the dog and the child, in turn, starts to berate the dog-yelling at him in the same kind of tone of voice.

3. Dog gets into chicken livers. Mother yells loudly, "Get down and get out of here dog," smacks him and shoos him out of the kitchen. A few minutes later the dog comes back in and the child imitates the mother, waving her arms, yelling at and hitting the dog.

4. Dog chokes and child laughs hilariously.

5. Child is squeezing a kitten's neck. Mother is worried that he might be able to hurt it. So she wraps her hands around the child's neck, to give him the idea of how unpleasant it is to have one's neck squeezed. He drops the kitten and she stopped squeezing.

6. Mother fusses at the dog. Child goes up to the dog, stomps her foot, jabbers to him - really trying to tell him off, calling him "Bad" and so on.

*Excerpted from mother's observational records.

with which $\mathrm{s} / \mathrm{he}$ handles the child when the child is distressed. This is one kind of index of the parent's empathy toward the child. Also, important are the parent's teachings and emotional reactions when parent and child view someone who is hurt or upset. For example, does the parent model altruism to the victim by helping, consoling, and so on, does $\mathrm{s} / \mathrm{he}$ reassure the child, or does $\mathrm{s} / \mathrm{he}$ ignore the situation entirely? The parent also plays a significant role when the child causes distress. Children's acts of aggression (e.g., hitting father, pulling the cat's tail) provide further occasions for teaching. Caregivers may use a variety of techniques here, sometimes in combination. These include for example, (a) power assertion (physical punishment or restraint), (b) withdrawal of love (e.g., sending the child to his room or coldly ignoring him), (c) verbal prohibitions ("stop it!"), (d) suggesting a positive, alternative behavior ("why don't you pet kitty instead of pulling on him?"), (e) reasoning or explanations about the consequences for the other ("you make Joey feel bad when you take his toy"; "that hurts Blacky when you step on his paw"), (f) perspective-taking, "Remember what it felt like when your foot got caught?", and (g) ignoring the situation. Some of these parental techniques are also illustrated in Table 1.

The content (or substance) of children's prosocial actions often appeared to have been learned (imitated) from the parents' own actions (e.g., mother shows child how to pat gently, or put on a Band-Aid). A very major parental influence had to do with the ways in which children were disciplined for hurting others. Mothers who had the most prosocial children used the following techniques: (1) They gave clear 
explanations about the negative consequences for the victim when the child hurt others; (2) they were sometimes moralistic and judgmental ("it's not nice to bite"; "I don't want to be near you when you act like that"); (3) they provided their children with general rules about physical aggression toward people and animals ("you must never hurt others"); and (4) they firmly prohibited their children from hurting others in specific situations and suggested positive, alternative actions. The children were more likely to make reparation for distresses they had caused and to come to the aid of victims they had not themselves harmed. Mothers who used this constellation of disciplinary techniques also tended to be highly empathic and sensitive to the needs of their own children when they themselves experienced distress.

The strong relationships between maternal practices and early child (prosocial) behaviors suggests that this is a time in the child's life when there is special receptivity and sensitivity to environmental influences, and hence to teachings about kindness toward others. A follow-up study of these families five years later showed that those children who showed high levels of generalized altruism and remorse over hurting others as toddlers were also the more altruistic children by the time they entered school (Cummings et. al., in press). Thus, we must take seriously the possibility that basic humane attitudes and behaviors are laid down in the first years of life and teachings can begin then. Young children can be made to understand that animals as well as people, have feelings, are receptive to affection, and sometimes require consolation.

Children's imitations of parental behaviors were by no means restricted to parents' prosocial actions (e.g., see Table 2). In at least half of the families studied, parents showed anger to animals and children imitated parent's expressions of anger and disciplinary action. This included episodes of shouting at and hitting animals. Sometimes we would see the young child embellish the parent's punitive action by yelling and hitting when the parent had just shouted. In some families, this appeared to be part of a consistent pattern. For example, one mother described an incident in which she yelled at the dog, picked him by the collar and "sort of" threw him down. In her words-"I get very violent with him because he really annoys me sometimes; I think I even kicked him." She noted that usually when she does this her one-year-old becomes frightened or angry too, but this time that didn't happen. Perhaps the child was already developing defensive coping strategies. We also saw the other extreme-families where pets were treated with respect and accorded family status. In such homes, children were often unusually responsive to the plights of pets. In one family, when the dog sneezed, the two-year-old boy 
would bring a kleenex to blow its nose, and when the dog hiccupped, the child tenderly kissed its nose. When the mother brushed the dog and hair came out, the boy interpreted it as a hurt and tried to shield the dog from the mother while anxiously attempting to pat the hair back on.

Humane and inhumane orientations of children thus may derive from the values fostered and the treatment of animals provided within the family. We have identified some of the parental practices that may promote compassion and dampen aggression. We found that mothers' communications about the need for humane behavior occur most frequently and with special intensity when their young children are themselves harming others. However, in another study of preschool children we found that young children can also be taught to help when they are bystanders to another's distress. An experimental research approach was used. Different learning environments were created to determine what kind of caregiver practices were most likely to produce generalized altruism in bystander circumstances.

\section{THE TEACHING OF GENERALIZED ALTRUISM}

Four experimental environments were developed to represent configurations of rearing conditions that differed in the adult's nurturant relationship with the child, and in how she conveyed her own prosocial principles, feelings, and behavior. The children were from middle-class and upper-middle-class families. They were assigned to nursery school groups in which an adult provided either highly nurturant or relatively aloof, matter-of-fact care. These experimental conditions took place in 30-minute periods in the nursery school over a period of two weeks. Following these "histories of rearing" the adult provided one of two kinds of programmed experiences that dealt with prosocial content. In type "A" conditions, the adult expressed prosocial principles and values in relation to many incidents of distress presented in pictures and in miniature play materials (dioramas depicting a child, an adult, or an animal in some kind of situation in which help was needed). The adult's reactions to these symbolized distresses combined inductive reasoning, positive emotional involvement, modeling of help, and provision of information. Thus, she explained, "Look, this little bunny is caught in the bush and can't get out. Poor bunny must be scared. I am going to help it out of the bush so it can get back to its mother. There, that makes the bunny feel better." The child would then have a turn at helping. Type " $B$ " conditions included the preceding procedures, with the important addition of the adult's responding similarly to programmed distresses that involved interaction with real people 
and animals (e.g., a teacher dropping her pencils, a cat tangled in yarn, etc.). These training conditions took place over several weeks. Both sets of rearing techniques provided the child with information intended to help the child to recognize cues of distress and feelings of the victim; to demonstrate ways of helping, and to indicate the consequences of such helping for the victim. The " $A$ " and " $B$ " procedures differed in two important respects: (1) Principles expressed by the adult in A conditions were only at the level of the hypothetical or abstract; in B conditions principles were put into practice with real consequences for the distressed persons. (2) Prosocial modeling by the adult in $\mathrm{B}$ conditions involved interaction with the distressed person which gave the adult the direct experience of the consequences of her prosocial interventions. High and low nurturant histories were used with each training type. These four conditions were intended as a study of configurations of rearing conditions as they are practiced in real life by parents and experienced by children. All four conditions resulted in more symbolic altruism than the control condition where no forms of teaching were done. One of the four configurations of rearing conditions produced a significantly higher frequency of real helping behavior from the children and more verbal expressions of sympathetic feelings than the other three conditions. It was an adult with whom the child had a history of a nurturant relationship and who provided the child with the model of her own caring behavior for others in both symbolic and real interactions with those in need. Also, in this condition, the adult's prosocial interactions involved child, adult and animal victims of distress and has clear cognitive and positive affective accompaniments. The adult provided the child with information about the victim's experience, the adult's own feelings, and the consequences of her prosocial intervention. The same set of rearing conditions that produced the highest levels of altruism in these children was similarly effective with a group of lower-class children in a replication study (Yarrow, Scott and Waxler 1973).

If we were to generalize from these experimental findings to child-rearing in the real world, we would conclude that the parent who is altruistic toward others but is cold with his child is not going to have much success in developing generalized altruism in his child. Further, the parent who conveys his moral values as principles only, but does not translate these into real, caring actions, accomplishes a similar limited kind of learning in the child. Generalized altruism appears to be best learned from parents who both inculcate the principles and show real altruism in their everyday interactions. And their practices toward their children are consistent with their general altruism. 


\section{SUMMARY AND CONCLUSIONS}

Our research provides substantial evidence of empathy and altruism in children at ages well before many theories would have it occur. The tendencies of young children sometimes to be egocentric, dependent, lacking in competence, demanding, narcissistic, and so on, have been emphasized in many theories of personality and cognitive development. Hence, we have been inclined to ignore their tender, prosocial side and the fact that they do have considerable social skills. Also contributing to an inaccurate view of young children as very limited in their empathic capacities are the research methods used. Cognitive/developmental studies often rely on interviews of children and this puts young children at a particular disadvantage. Often they cannot put into words the reasons for their acts of caring, they cannot state abstract principles of justice, and they evidence primitive, unsophisticated verbal understanding of moral issues. They then become labelled as functioning at a low stage of moral development, and are stereotyped as hedonistic, exploitative, negativistic, dominionistic, and so on in their orientations toward others. These characterizations are based on poorly applied understanding of young children's words rather than on their deeds and their expressed emotions.

While some studies report that children become more prosocial with age, many other studies of cooperation, comforting, helping, and sharing do not show the expected age increase (Radke-Yarrow, ZahnWaxler and Chapman 1983). The research situations in which older children have been shown to be more likely than younger children to manifest prosocial behavior are research situations in which the victim's plight is portrayed symbolically and children must share with a hypothetical other (i.e., as in giving to charity). Older children will necessarily be better able to understand such abstractions and representations of distress and will have developed greater competencies for prosocial behavior that requires these abilities. This does not mean, however, that children necessarily develop a greater emotional capacity for empathy as they grow older. In fact, the opposite sometimes may be true for many because they have had more time to learn other values and practices, to treat distress as routine, and to have developed defenses for shutting out their own and others pain. It is reasonable to assume that children of all ages are capable of learning to be kind. The ways in which they learn will differ considerably. This is an area where much research is needed to help plan the most effective curricula for children of different ages.

Our research is not unique in finding that young children's capacities for concerned feelings and behaviors far outstrip their verbal competencies. Increasingly, there are studies that corroborate the 
occurrence, in the first years of life, of children's understanding of others' inner feelings; children's abilities to cooperate, take turns with others, and negotiate conflicts, show willingness to share with peers and adults, and manifest capabilities for giving help (e.g., Bretherton, McNew and Beeghley-Smith 1981; Eckerman, Whatley and Kutz 1975; Rheingold, Hay and West 1976; Ross and Goldmam 1977; Hay and Ross 1982). These findings are not merely an academic issue. They influence whether we view young children as altruistic or hedonistic, and determine when, if, and how we will attempt to teach them compassionate behavior. Our data, and those of others, indicate that training should begin very early and that it should recognize the child's innate empathic sensitivies. It is commonly recommended that children be at least five to six years old before they are allowed to have pets because this is when they can first begin to assume some real responsibility. This decision precludes exposure to animals in those important early years of life where basic orientations are established.

The research has specific implications for curricula that are designed to develop and encourage empathic and humane behavior in young children. The following factors have been found to be important: (a) having warm and accepting relationships with the parent/ teacher if the learning is to generalize, (b) using training materials that realistically portray feelings and distress, (c) giving the child direct experience with real helping, (d) beginning teaching very early in the child's life and making it a family affair, (e) using explicit explanations about feelings and circumstances of the victim, i.e., actively evoking empathy in the child, and (f) stating general codes or principles about altruism, aggression, and morality, in simple, explicit terms. Many of these notions are probably already part of existing curricula and hence may represent what is already conventional wisdom to some. To large numbers of people, however, it is not common knowledge that empathy and humane behavior can be taught and learned even in the earliest years of life.

To summarize, as early as the second year of life, one can begin to teach children the rudiments of a sense of responsibility for other people and animals. This teaching task should continue through childhood, with an attempt both to retain the child's early empathic proclivities and to be sensitive to the changing cognitive and symbolic capacities that occur with development. It is possible to show even young children specific ways of helping and caring for others. The verbal messages and the physical demonstrations of appropriate actions need to be simple, direct, concrete, consistent, and repeated in a variety of contexts throughout the early years of life. It is especially important with toddlers and preschoolers (and with older children as well) that the teaching not always be at an abstract symbolic levels, (i.e., 
with pictures, stories, teddy bears, etc.) Rather, "hands on" experiences with real animals and persons, with their needs, their discomforts, and the specific caretaking they require will be necessary to equip children with the knowledge and motivation for responding humanely.

The mothers' reports in the longitudinal study of altruism provided us with many detailed narrative records of family interaction with pets. Based on clinical evaluations of these reports we offer the following observations and generalizations. Many of the families had pets but there was considerable variability in the ways in which animals were incorporated into the family and in their specific roles and functions. Parents vary considerably in how much they praise and reward children's nurturing of animals and how much teasing they tolerate. Some parents find the child's abuse or aggression "cute" while others firmly apprise their children of the distress this creates for the animal. There are differences (described earlier) in the techniques parents use to prevent the child from hurting and encourage the child to be more caring. Hence, parents presumably differ in the extent to which they believe animals have feelings, are receptive to affection, and require comfort.

Some parents clearly use pets as the scapegoats for other family and personal problems: in volatile, angry families, animals are the recipients of displaced aggression, receiving more than their share of hostility for minor misdeeds. Some of the parents give mixed messages to their children about the value of the pets and the children, in turn, reflect this ambivalence in their own treatment of animals. Thus, they can be seen to alternate between affection and abuse, with little awareness of this inconsistency in their treatment. The research literature and common sense would lead us to expect that children will learn to be caring, or abusive, or indifferent to animals depending on whether they see the parent behave in a similar way. It is more complicated, however. Some children may be relatively unresponsive to parental teachings and some may react against their parents. One little girl, for example, sided with the animal in situations of conflict and consistently tried to protect it against parental punishment, sometimes literally putting herself in the middle. This kind of compassion (i.e., early adoption of the defender role) thus may have very different origins from the compassion based on positive teachings. Even if families have pets early in child's life, this does not assure a good learning situation. There is considerable variability in early family experiences with animals; children will come to early training and education programs with very different attitudes, behavior styles, values, and emotional orientations toward animals. These patterns may al- 
ready be pervasive and entrenched. Teaching techniques then will have to be adapted to reach each child.

It is interesting to speculate concerning why domestic cats and dogs evolved. Mostly, we take them for granted but they are an anomaly in the animal kindgom in terms of (a) their propensity to form more intense social attachments outside of their own species (i.e., to humans) than within it, and (b) their ability to elicit strong expressions of affect from humans. These mutual attachments were thought to have evolved originally because cats and dogs were useful to human physical survival, - in keeping down the rodent population, in protecting, and defending humans, and so on. Yet, even when these needs no longer existed, people continued to have pets, perhaps more to fill psychological and emotional needs. The extensive recent use of pets as "therapists" attest to their remarkable capacity for reducing stress and providing companionship, comfort, and pleasure to others (Katcher and Beck 1983). We make animals an important part of children's lives from infancy onward. As babies they are given stuffed animals of all kinds and many of their first experiences with comfort (given and received) are with these play objects. The first dreams of children are reported to have more animal than human themes. Also, many early educational materials make use of animal characters. Some people believe that there is a natural, special affinity or empathic bond between young children and animals (though there is the potential for cruelty as well). We have many reasons for giving pets to children. Pets provide companionship and comfort, they provide an opportunity for less ambivalent emotional relationships, they may help to ameliorate family tensions. Some mothers, for example, indicate that the child goes to the family's cat or dog for comfort after having been disciplined. Animals also provide an opportunity to learn to be responsible for others, to be gentle, and to discipline effectively. Because the life span of a pet is often shorter than the periods of childhood and adolescence of humans, children's first experiences with suffering, death and mourning, issues of mortality and immortality often will be in relation to their pets. Thus, animals provide an arena for teaching and learning (at both cognitive and emotional levels) about many of the major issues and struggles basic to existence.

Darwin's travels and observations led him to reaffirm, as have others before and after him, that man is not the center of the universe. Man is connected to a larger web of life. We are a fellow species who need to share the earth with other species. Family pets may serve a very special purpose of reminding us of this connection between human life and animal life and the emotional needs we have in common with other animals. 
Many of the issues that concern us here are conveyed with eloquence and insight in de Saint-Exupéry's book, The Little Prince (1943). The prince, a young boy, travels to many planets, and talks to many people in his quest to know about the meaning of life. At last, on earth, he learns from a fox what is important. The boy meets a wild fox one morning and invites him to play. The fox tells the prince he cannot play with him because he is not yet tame. The prince asks what it means to tame and the fox replies, "It is an act too often neglected. It means to establish ties. Until we establish ties, neither of us is special to each other. But if you tame me, then we shall need each other. To me you will be unique in all the world. To you, I will be unique in all the world," - "You become responsible forever for what you have tamed." The fox teaches the boy how to tame him and they form a close bond. Eventually they must part and the fox is about to cry. The prince speculates that it might have been better never to have met because of the pain of separation. The fox assures the prince that it is infinitely better to have formed the relationship because through the process, they have become unique in all the world. It is this complex and poorly understood process of relationship formation, whether between people or between people and animals, that helps to foster empathy and diminish aggression. 


\section{REFERENCES}

Bretherton, I., McNew, S., and Beeghley-Smith, M. 1981. Early person knowledge as expressed in gestural and verbal communications: When do infants acquire a "theory of mind?" In: Infant social cognition. Hillsdale, New Jersey: Lawrence Erlbaum Associates.

Burleson, B.R. Comforting communication. Understanding interpersonal communication: Social cognitive strategic processes in children and adults. Beverly Hills, California: Sage, in press.

Cummings, M., Zahn-Waxler, C., Iannotti, R.J., Hollenbeck, B., and Radke-Yarrow, M. Early organization of altruism and aggression: Developmental patterns and individual differences. In: Zahn-Waxler, C., Cummings, E.M., and Iannotti, R.J. eds. Altruism and aggression, social and biological origins. Cambridge Press, in press.

de Saint Exupéry, A. 1943. The Little Prince. New York: Harcourt, Brace and Javanovitch.

Dymond, R.F. 1945. A preliminary investigation of the relation of insight and empathy. Journal of Consulting Psychology 12(4):228-33.

Eckerman, C.O., Whatley, J.L., and Kutz, S.L. 1975. Growth of social play with peers during the second year of life. Developmental Psychology 11:42-49.

Eisenberg, N. 1983. The socialization and development of empathy and prosocial behavior. The Humane Society of the United States, Fort Worth, Texas, October 1983. Symposium: Can love be taught: Animals, empathy and education.

Feshbech, S. and Feshbach, N. Altruism and aggression: A personality perspective. In: Zahn-Waxler, C., Cummings, E.M., and Iannotti, R.J. eds., Altruism and aggression: Social and biological origins. Cambridge Press, in press.

Hay, D.F. and Ross, H.S. 1982. The social nature of early conflict. Child Development 53:105-13.

Hoffman, M.L. 1975. Empathy, role-taking, guilt, and the development of altruistic motives. In:Likona, T. ed. Moral development and behavior. New York: Holt, Rinehart, and Winston.

Hogan, R. 1973. Moral conduct and moral character: A psychological perspective. Psychological Bulletin 79(4):217-32.

Katcher, A.H. and Beck, A.M. 1983. eds. New perspectives on our lives with companion animals. Philadelphia: University of Pennsylvania Press.

MacLean, P. 1982. Evolutionary brain roots of family, play, and the isolation call. The Adolph Meyer Lecture, 135th Annual Meeting of the American Psychiatric Association, Toronto, Canada, May 18.

Madsen, M.C. and Shapira, A. 1977. Cooperation and challenge in four cultures. Journal of Social Psychology 102:189-95.

Meade, G.H. 1934. Mind, self, and society. Chicago: University of Chicago Press.

Miller, N.E. 1983. Understanding the use of animals in behavioral research: Some critical issues. In:Sechzer, J.A. ed. The role of animals in biomedical research. Annals of the New York Academy of Sciences, Vol. 406:113-8.

Olinick, S.L. 1980. The psychotherapeutic instrument. New York: Aronson.

Panksepp, J. The psychobiology of prosocial behaviors: Separation distress, play and altruism. In:Zahn-Waxler, C., Cummings, E.M., and Iannotti, R.H. eds. Altruism and aggression: Social and biological origins. Cambridge Press, in press.

Parke, R.D. and Slaby, R.G. 1983. The development of aggression. In:Mussen, P.H. ed. Carmichael's manual of child psychology (Vol. IV, 4th ed., Hetherington, H., ed.) New York: John Wiley and Sons. 
Piaget, J. 1965. The moral judgment of the child. Glencoe, Ill.: Free Press. (originally published, 1932).

Radke-Yarrow, M., Zahn-Waxler, C., and Chapman, M. Children's prosocial dispositions and behavior. In:Mussen, P.H. ed. Carmichael's manual of child psychology (Vol. IV, 4th ed., Hetherington, E., ed.), New York: John Wiley and Sons, pp. 469-546.

Rheingold, H., Hay, D., and West, M. 1976. Sharing in the second year of life. Child Development 47:1148-58.

Rogers, C.R. 1957. The necessary and sufficient conditions of therapeutic personality change. Journal of Consulting Psychology 21:95-103.

Ross, H.S. and Goldman, B.D. 1977. Establishing new social relations in infancy. In:Alloway, T., Krames, L. and Plinar, P. eds. Advances in communication and affect. Vol. 4. New York: Plenum Press.

Sagi, A. and Hoffman, M.L. 1976. Empathic distress in the newborn. Developmental Psychology 12:175-6.

Shantz, C.U. 1983. Social cognition. In:Mussen, P.H. ed. Carmichael's manual of child psychology, (Vol. III, 4th ed.), Flavell, J.H. and Markman, E.M. eds. New York: John Wiley and Sons.

Simner, M.L. 1971. Newborn's response to the cry of another infant. Developmental Psychology 5:136-50.

Wilson, E.O. 1975. Sociobiology: The new synthesis. Cambridge, Mass.: Harvard University Press.

Yarrow, M., Scott, P., and Waxler, C. 1973. Learning concern for others. Developmental Psychology 8:240-60.

Zahn-Waxler, C., and Radke-Yarrow, M. 1982. The development of altruism: Alternative research strategies. In:Eisenberg, N. ed. The development of prosocial behavior. New York: Academic Press. pp. 109-37.

Zahn-Waxler, C., Radke-Yarrow, M., and King, R. 1979. Child rearing and children's prosocial initiations toward victims of distress. Child Development 50:319-30. 